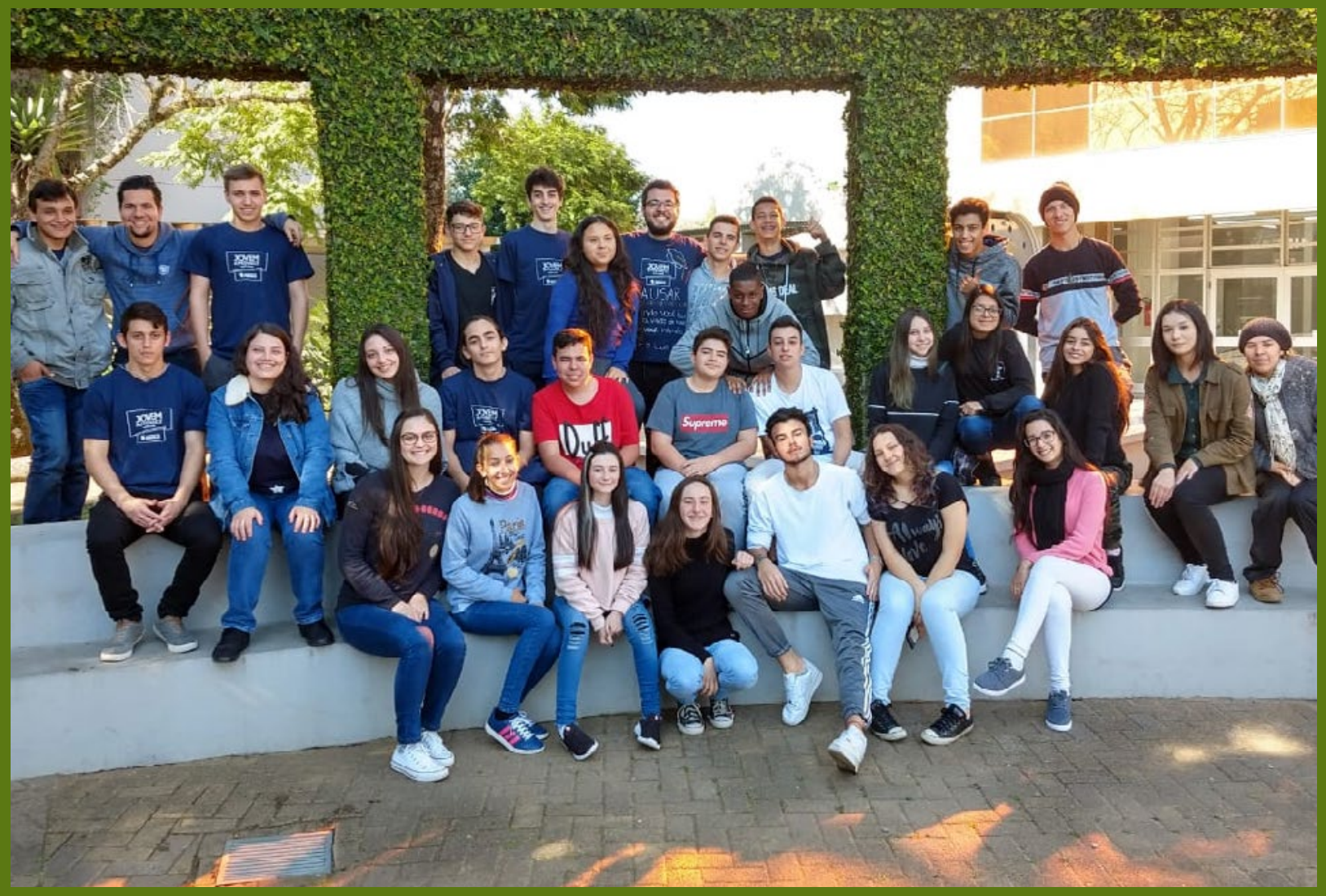

\title{
A desconstrução da história
} única

\section{Luís André Gonçalves Werlang ${ }^{1}$} luisandregw@gmail.com

\section{Lovani Volmer ${ }^{2}$} lovaniv@feevale.br

1 Licenciado em Letras - Português e Inglês pela Universidade Feevale.

2 Doutora em Letras, ênfase em Leitura e Linguagens (UCS). Professora na Universidade Feevale. 
Este relato de experiência trata das oficinas de Língua Portuguesa do Projeto Jovem Aprendiz, em uma instituição comunitária gaúcha. Com o objetivo inicial de trabalhar com as habilidades do século XXI, os alunos foram instigados a pensar criticamente na língua e sobre como ela é usada para construir e moldar identidades. A partir da palestra "O perigo de uma história única" (ADICHIE, 2009), desenvolveram-se propostas de atividades visando à desconstrução, pela língua, de estereótipos e histórias únicas.

Palavras-chave: Linguagem. Identidade. História única. Desconstrução. Sala de aula.

ABSTRACT

This experience report regards the Portuguese classes of the Jovem Aprendiz Project, at a community institution in the south of Brazil. With the primary objective of working with the 21st century skills, the students were inspired to critically think about language and how it is used to build and shape identities. Stemming from the speech "The danger of a single story" (ADICHIE, 2009), activities were developed aiming the deconstruction of stereotypes and single stories through the use of language.

Keywords: Language. Identity. Single story. Deconstruction. Classroom.

\section{Relato de experiência}

"As histórias importam. Muitas histórias importam. As histórias foram usadas para espoliar e caluniar, mas também podem ser usadas para empoderar e humanizar. Elas podem despedaçar a dignidade de um povo, mas também podem reparar essa dignidade despedaçada." (CHIMAMANDA, 2019, p. 32)

As palavras têm força. Muitas vezes isso nos passa despercebido e é pouco discutido em sala de aula. 0 modo como nos comunicamos, o que comunicamos e como interagimos com o outro consolidam as nossas relações interpessoais. Muitos estudos, em especial aqueles baseados em Bakhtin (2014), apontam que nos constituímos na pluralidade de vozes e que a língua está diretamente ligada às relações de poder, construídas pelas interações sociais, que, por sua vez, são realizadas por meio da língua.

Foi a partir dessas considerações e no intuito de desenvolver habilidades do século XXI que o trabalho aqui exposto foi realizado, com um grupo de jovens entre 15 e 19 anos, participantes do projeto Jovem Aprendiz, em uma instituição comunitária gaúcha, nas oficinas de Língua Portuguesa. Com enfoque multidisciplinar, o Projeto possibilita, juntamente com as oficinas de Informática e Psicologia, a discussão de diferentes temáticas pertinentes à inserção do adolescente no mundo do trabalho e a sua transição para a vida adulta.

Partindo do princípio de que "ensinar não é transferir conhecimento, mas criar as possibilidades para a sua própria produção ou a sua construção" (FREIRE, 2014, p. 47), as oficinas de Língua Portuguesa foram organizadas a partir de materiais autênticos e conforme os interesses e as bagagens dos seus participantes. Os encontros explicitados neste relato de experiência ocorreram semanalmente, com duração de 3 horas, durante o primeiro semestre de 2019, e foram ministrados por um acadêmico do curso de Letras da instituição.

Nesse contexto, visando unir aspectos da educação e aprendizagem que se relacionem ao mercado de trabalho eà cidadania, consideramos, na proposição das atividades, as habilidades profissionais elencadas pelo Fórum Econômico Mundial para o século XXI, quais sejam: 1. Solução de problemas complexos; 2. Pensamento crítico; 3. Criatividade; 4. Gestão de pessoas; 5. Relacionamento interpessoal; 6. Inteligência emocional; 7. Julgamento e tomada de decisão; 8. Orientação de serviço; 9. Negociação; 10. Flexibilidade cognitiva.

Assim sendo, nas duas primeiras oficinas, os alunos discutiram, em pequenos grupos, sobre competências cognitivas, interpessoais e intrapessoais e suas respectivas habilidades. A partir disso, discutimos sobre a importância da língua dentro de cada uma dessas competências, uma vez que ela está sempre presente como alicerce para construção, elaboração e comunicação de ideias. Com base nas discussões, a fim de consolidar o conhecimento construído, os alunos desenvolveram mapas conceituais sobre as competências e habilidades (Figura 1). 
Figura 1: Alguns dos mapas conceituais produzidos pelos alunos
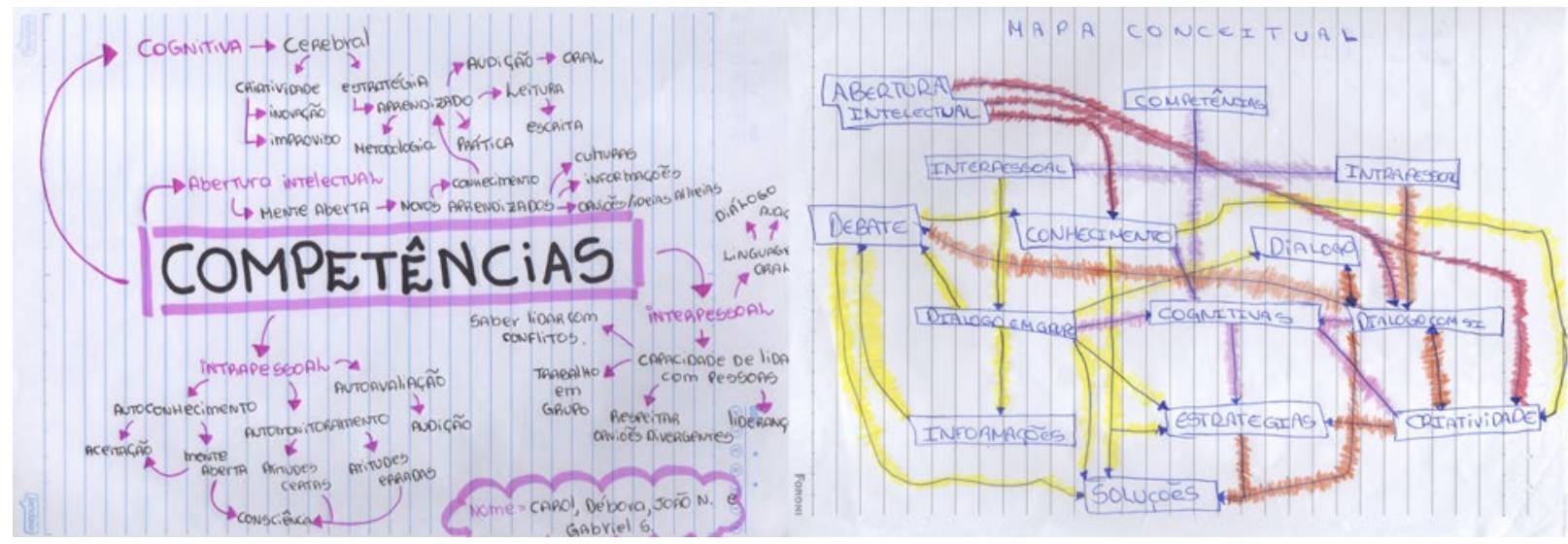

Fonte: Produção original dos autores.

Decidimos, no coletivo, que daríamos maior ênfase às competências inter e intrapessoais, por considerar que as cognitivas já dominam o ambiente escolar. Desse modo, algumas palavras-chave nortearam nossa prática, em especial: criatividade, pensamento crítico, abertura intelectual, escuta ativa e empatia. Essas habilidades seriam incorporadas na prática do diálogo e da escuta, visando trabalhar com o objeto de estudo da oficina: a língua.

Tendo isso em vista, assistimos à palestra "O perigo de uma história única" (TED Talks, 2009), da escritora nigeriana Chimamanda Ngozi Adichie. A partir desse vídeo, foi possível refletir e discutir sobre um dos pontos centrais das oficinas: a não existência de um único lado da história. Segundo Chimamanda, o contato único com livros americanos e britânicos em sua infância limitou o universo de sua imaginação, pois os modos de vida que via representados nos livros não condiziam com os seus e os de seu povo. Assim, considera que a descoberta de escritores africanos salvou-a de ter uma históriaúnica sobre o que pode ser a literatura. Reconheceu e questionou, a partir disso, como as culturas do continente africano são representadas no mundo.

Em um certo momento de sua palestra, Chimamanda questiona como seria a história do "descobrimento" da América (referindo-se aos Estados Unidos) se ela começasse a ser contada pelas flechas dos indígenas e não pela chegada dos britânicos. Utilizando essa mesma reflexão, os alunos foram instigados a pensar como seria a história do "descobrimento" do Brasil pelo olhar dos grupos indígenas da época. É clara a falta de informação sobre esse momento histórico, no que se refere à atenção ao ponto de vista dos indígenas, que são muitas vezes apagados historicamente. Utilizando a pesquisa e a criatividade, os alunos realizaram produções textuais, em diferentes linguagens e gêneros, mostrando esse outro lado do início da história de nosso país. Muito presente em suas produções estava a crítica à violência e exploração contra os grupos indígenas por parte dos colonizadores.

Figura 2: Alunos do projeto apresentando sua esquete teatral

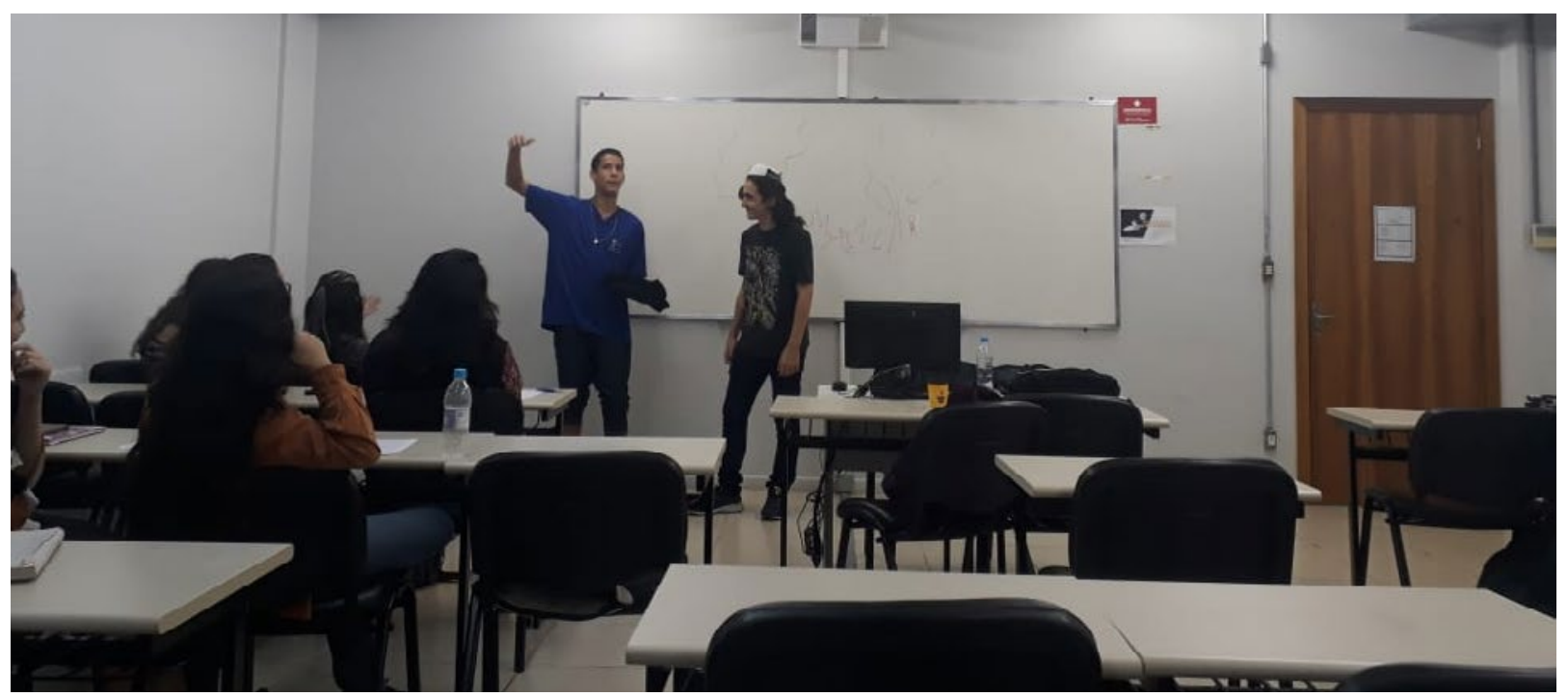

Fonte: Imagem original dos autores. 
Para continuar as reflexões sobre a versão única de uma história, propusemos aos alunos que pensassem em suas narrativas pessoais. Inicialmente foi realizada uma discussão em grupo sobre duas perguntas-chave: Quem conta a nossa história e como ela é contada?

Os alunos foram apresentados ao Museu da Pessoa (www.museudapessoa.org), um museu virtual e colaborativo, cujo acervo possui milhares de vídeos e imagens sobre pessoas de todas as regiões do Brasil contando sua história, o que nos mostra as múltiplas facetas do povo brasileiro. 0 Museu da Pessoa não apenas deixa claro o quão plurais nós somos, enquanto brasileiros, por exemplo, mas também aponta para a importância de nós mesmos narrarmos nossas histórias.

Com base nisto, os alunos foram levados a refletir sobre os seguintes questionamentos: Como eu me mostro ao outro? Como eu enxergo o outro e como o outro me vê? Em grupo, conversamos sobre os possíveis "filtros" que colocamos em nossa história quando a contamos para alguém ou quando escutamos a história de outra pessoa. Será que nos mostramos ou nos percebemos de igual forma?

A partir dessa discussão, os alunos se organizaram em duplas para escrever a biografia do colega. Esse foi um momento em que puderam exercer uma das habilidades, que, ao nosso ver, é uma das mais importantes da competência interpessoal: a escuta ativa. Assim, também, puderam conhecer melhor seus colegas ou amigos, fazendo perguntas que talvez não fariam no dia a dia.

Após finalizarem as escritas de suas biografias, os alunos puderam ler sua história pelo olhar do outro e ver como foram representados no papel, tendo em mente as reflexões feitas anteriormente.

\section{Figura 3: Os alunos realizando uma atividade de interação em duplas}

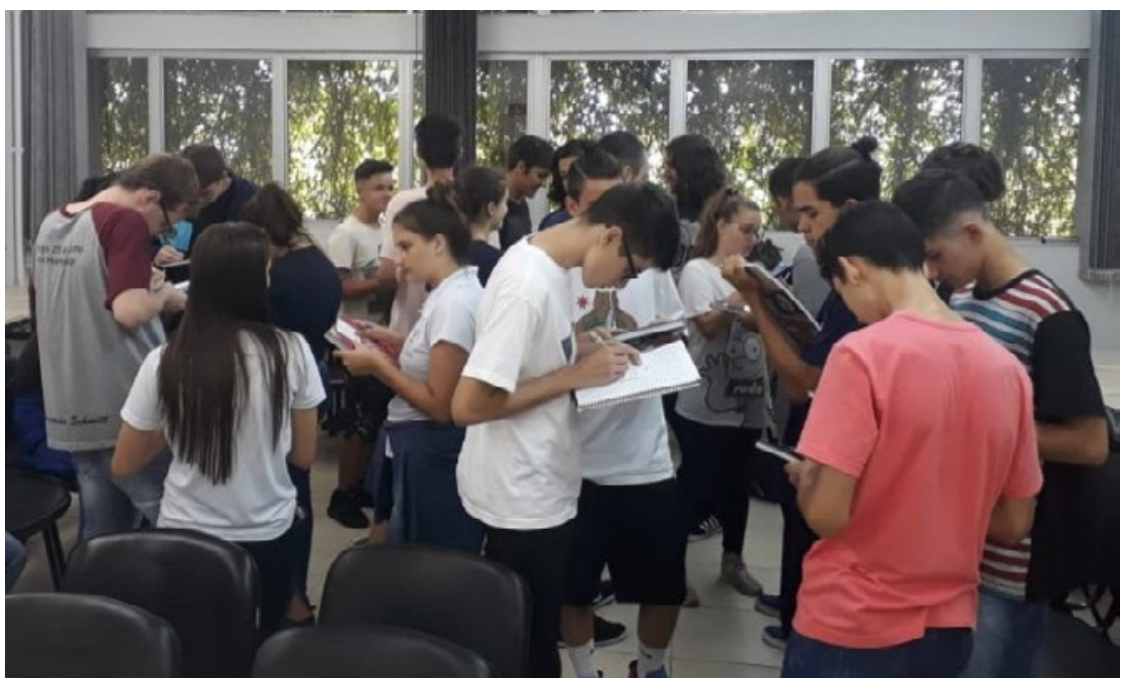

Fonte: Imagem original dos autores.

Das narrativas, os aprendizes foram, por fim, levados a refletir sobre a palavra. Qual o poder das palavras? Lembrando-se das questões levantadas por Chimamanda, discutimos sobre palavras que auxiliam na construção de uma identidade estereotípica do sujeito, que são usadas para descrever alguém e que, muitas vezes, são usadas em sentido pejorativo. A partir disso, trouxeram exemplos de xingamentos que já escutaram e que foram destinados a eles, como: gordo(o), magrelo(a), burro(a), vagabundo, vadia, corno, merda etc. Visando não expor ninguém, cada um escreveu sua(s) palavra(s) em um pedaço de papel e colocou-o em uma caixinha. Após isso, as palavras foram lidas para a turma e conversamos sobre seu impacto. Nesse momento da oficina, não existiam tabus sobre quais palavras deveríamos ou não falar.

Foram, então, apresentados à obra "O livro dos ressignificados", de João Doederlein, em que o autor inspirase em um dicionário para, com uma linguagem poética e com significados amplamente conotativos, ressignificar palavras, como amor, amizade, resiliência etc. Depois de lermos trechos do livro, foi proposto aos alunos que pegassemumapalavradedentrodacaixinhadepapéisemquehaviam colocado oseuxingamentoeressignificassem essa palavra. A questão levantada foi a seguinte: de que forma essa palavra poderia ser ressignificada, de modo a dar-lhe um sentido positivo e que empoderasse o sujeito que a utiliza como autorreferência? (Quadro 1) 


\section{Quadro 1: Exemplos de algumas das palavras ressignificadas pelos alunos}

\section{Grossa}

Mulher empoderada, determinada e independente, possui uma ampla visão de mundo e conhecimento. Não se abala em uma circunstância negativa, não tem receio de críticas e as usa a seu favor.

\section{Vagabunda}

Mulher com atitude que não se priva e nem depende de ninguém. Mulher decidida e que sabe o que quer, que enfrenta um mundo contra tudo e todos. Que é mulher sem medo de qualquer rótulo.

\section{Merda}

Serve de adubo. Contém os nutrientes necessários para a inicialização de um novo ciclo. Você provavelmente foi chamado de merda por não possuir os mesmos conhecimentos que a pessoa que te agrediu tenha. Mas não desanime... $\mathrm{Tu}$ tens muito conhecimento sobre êne coisas nas quais a pessoa sequer pensara. Ser um merda em algo, e reconhecer, é bom, pois serve de adubo para se iniciar um novo ciclo de aprendizados.

\section{Fonte: Produção original dos autores.}

Em seguida, ainda tratando do poder da palavra, refletimos sobre o poder positivo (e não negativo, como anteriormente) de determinadas palavras. Algumas das que surgiram na conversa em grupo foram: desculpa, eu te amo, respeito, amor, amizade etc. A partir disso, os alunos ressignificaram as palavras de sua escolha, individualmente ou em duplas. (Quadro 2)

\section{Quadro 2: Exemplos de mais algumas das palavras ressignificadas pelos alunos}

Amor

É sentir tudo e mais um pouco. Algo sem gênero, sem rótulos. É o beijo da mãe, o abraço do amigo, a cura para um peito doído.

\section{Liberdade}

É o direito de possuir autonomia e espontaneidade e de fazer o que bem entender, desde que não prejudique outro indivíduo. Contudo, só é possível alcançá-la se você mora fora da casa dos pais.

\section{Amizade}

É poder falar sobre qualquer assunto, mas também respeitar o silêncio de uma terça-feira nublada. É dividir o lanche, mesmo contra a vontade. É se entender pelo olhar. É compreender as dores, e caso isso não aconteça, oferecer um ombro amigo. É entender as referências aleatórias que são jogadas na roda.

É ter que ouvir piadas ruins.

\section{Fonte: Produção original dos autores.}

Por fim, no intuito de ampliar o alcance das discussões que fizemos e propiciar, pela palavra, que outras pessoas também possam ressignificar conceitos e, assim, seu olhar sobre si e o outro, foi proposto aos alunos que confeccionassem camisetas com seus ressignificados. (Figura 4) 
Figura 4: Alunos confeccionando uma camiseta do projeto

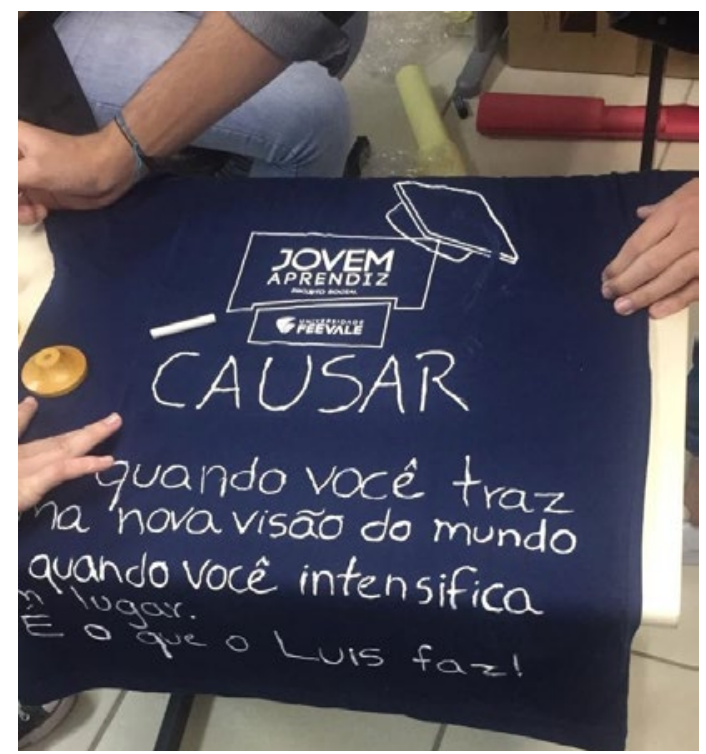

Fonte: Imagem original dos autores.

0 projeto ora apresentado tornou mais evidente a importância de dar espaço ao que Bakhtin (2014) chama de "multiplicidade de vozes sociais". A escola, o mercado de trabalho, e a sociedade de modo geral, são compostos por sujeitos, cada um com sua singularidade, mas inseridos dentro de determinados grupos sociais, também com suas particularidades, e desempenhando papéis sociais diferentes nos múltiplos momentos e contextos de interação. Somos heterogêneos em muitos aspectos, porém em busca da união pelo respeito e pela ética do viver em conjunto.

As oficinas de Língua Portuguesa no Jovem Aprendiz constituíram-se momentos de interação e troca de saberes, na construção do saber inacabado, em um ambiente em que todos ensinam e todos aprendem, demonstrando ser possível trabalhar de forma crítica e libertadora dentro da sala de aula, assim como já haviam dito Paulo Freire (2014) e bell hooks (2017), escritores que tiveram grande influência na prática docente aqui descrita. Buscou-se sempre tornar o ambiente acolhedor para todos, dando-lhes espaço para expressar opiniões, discutir pontos de vista e, talvez mais importante, ouvir o que outro tem a dizer, na busca por uma sociedade mais equânime e empática.

Figura 5: Uma das turmas no encerramento da oficina

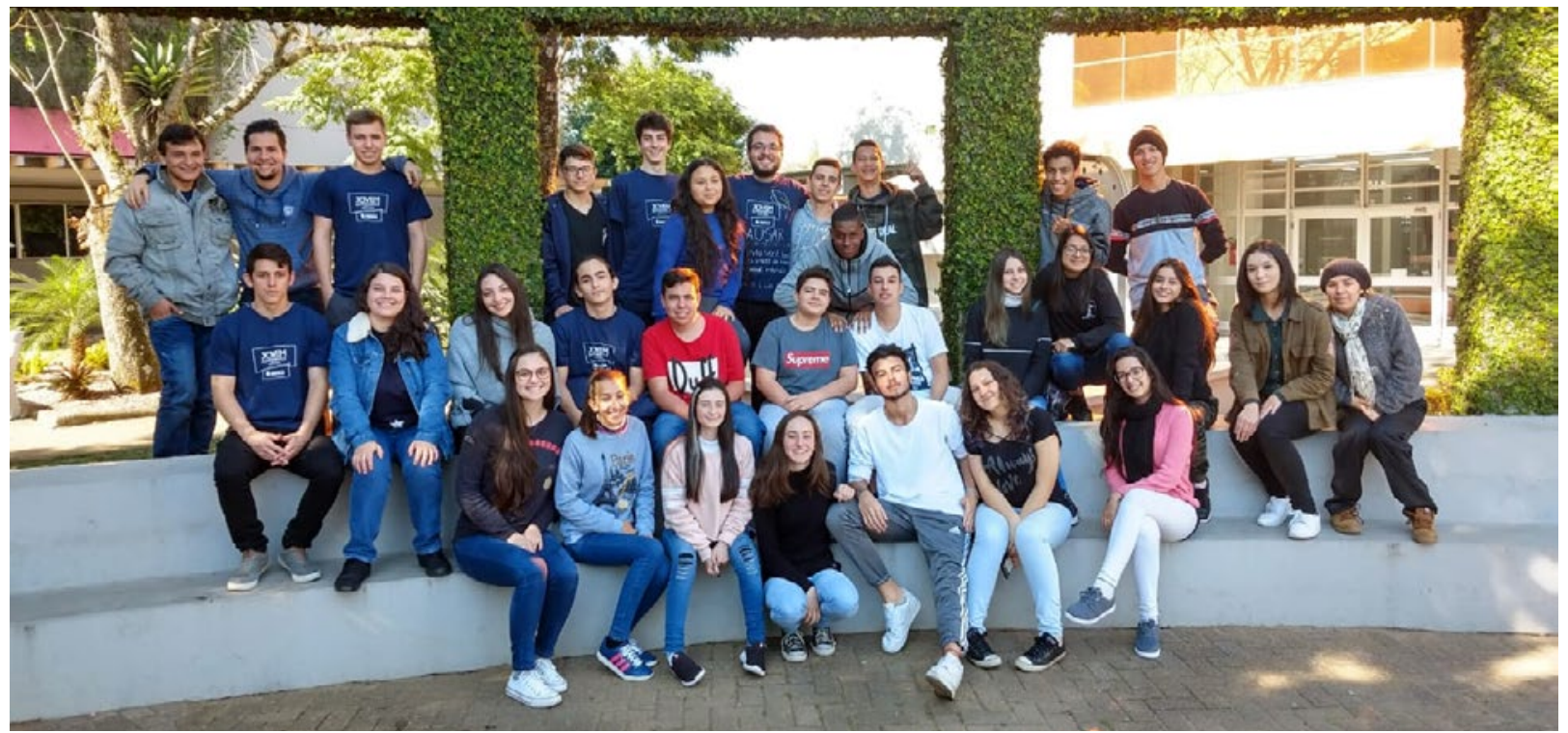

Fonte: Imagem original dos autores. 


\section{Referências}

ADICHIE, Chimamanda Ngozi. O perigo de uma história única. TED Talks, 2009. Disponível em: <https://www. youtube.com/watch?v=D9lhs241zeg\&t=650s $>$. Acesso em: 20 set. 2019.

ADICHIE, Chimamanda Ngozi. 0 perigo de uma história única. São Paulo: Companhia das Letras 2019.

BAKHTIN, M. M. Marxismo e filosofia da linguagem: problemas fundamentais do método sociológico da linguagem. São Paulo: Hucitec, 2014.

DOEDERLEIN, João. 0 livro dos ressignificados. São Paulo: Paralela, 2017.

FREIRE, Paulo. Pedagogia da autonomia. Rio de Janeiro: Paz e Terra, 2014.

HOOKS, bell. Ensinando a transgredir: a educação como prática da liberdade. São Paulo: WMF Martins Fontes, 2017. 